\title{
Aortic Distensibility and Extent and Complexity of Coronary Artery Disease in Patients with Stable Hypertensive and Nonhypertensive Coronary Artery Disease
}

\author{
Zafer Elbasan Durmuş Yıldıray Şahin Mustafa Gür Gökhan Gözübüyük \\ Rabia Eker Akıllı Nermin Yıldız Koyunsever Caner Türkoğlu Ali Kıvrak \\ Arafat Yıldırım Murat Çaylı \\ Department of Cardiology, Adana Numune Education and Research Hospital, Adana, Turkey
}

\section{Key Words}

Aortic distensibility · SYNTAX score · Coronary artery

disease $\cdot$ Hypertension

\section{Abstract}

Objective: To assess the relationship between aortic distensibility (AD) and the extent and complexity of atherosclerotic lesions assessed with SYNTAX score (SS) in patients with stable coronary artery disease. Subjects and Methods: Three hundred and seventy-six consecutive patients ( 230 males and 146 females; mean age: $61.6 \pm 9.9$ years) with angiographically proven coronary artery disease were included in the study. The SS was calculated using the SS algorithm on the baseline diagnostic angiogram in the 376 patients. AD was calculated from the echocardiographically derived ascending aorta diameters and hemodynamic pressure measurements in all patients. Frequencies of risk factors, biochemical and hematological data were recorded. The patients were divided into two groups according to the median $A D$ value as $A D_{\text {low }}$ and $A D_{\text {high }}$ groups. Results: The $S S$ was higher in the $A D_{\text {low }}$ group compared with the $A D_{\text {high }}$ group $(18.5 \pm 10.2$ vs. $8.3 \pm 5.9, p<0.001)$. The AD was independent-

\section{KARGER}

E-Mail karger@karger.com www.karger.com/mpp (c) 2013 S. Karger AG, Basel 1011-7571/13/0223-0260\$38.00/0 Open access

This is an Open Access article licensed under the terms of the Creative Commons Attribution-NonCommercial-NoDerivs 3.0 License (www.karger.com/OA-license), applicable to the online version of the article only. Distribution for non-commercial purposes only. ly related to age ( $\beta=-0.104, p=0.019)$, hypertension ( $\beta=$ $-0.202, p<0.001)$ and SS $(\beta=-0.457, p<0.001)$ and was more strongly associated with SS in hypertensive patients compared to nonhypertensive patients $(r=-0.524$ vs. $r=-0.414$, $p<0.001$ for all). Conclusion: The findings showed that impaired AD might be an independent predictor for the severity of coronary atherosclerosis, particularly in patients with hypertension.

Copyright $\odot 2013$ S. Karger AG, Basel

\section{Introduction}

Normal aortic function is compromised when the aorta loses its elasticity, resulting in stiffening of the aorta [1]. There is growing evidence that aortic stiffness is a subclinical marker of early atherosclerosis [1-5]. Aortic distensibility (AD) is a measurement of vascular elasticity, which reflects the stiffness of the aorta [6]. However, AD is markedly decreased in patients with known coronary artery disease (CAD) and is inversely proportional to the severity of CAD [7-11]. In addition, AD plays a key role in maintaining normal coronary blood flow [12]. 
The SYNTAX score (SS) is a lesion-based angiographic scoring system originally devised to grade the complexity of CAD [13]. It is related to adverse cardiovascular events and predicts mortality and morbidity in patients with CAD [14]. Although the inverse relationship between $\mathrm{AD}$ and atherosclerosis is well known [7-11], the possible relation between $\mathrm{AD}$ and the extent and complexity of disease in patients with stable CAD assessed using SS has not been clearly determined yet. In this study, we aimed to assess the relationship between $\mathrm{AD}$ and the extent and complexity of atherosclerotic lesions in patients with hypertensive and nonhypertensive stable CAD.

\section{Subjects and Methods}

\section{Study Population}

In all, 376 consecutive patients (230 males and 146 females; mean age: $61.6 \pm 9.9$ years) with angiographically proven CAD admitted to our Cardiology Clinic for angiography between January 2012 and June 2012 were included. Angiography was performed for the investigation of ischemic heart disease based on clinical indications (typically chest discomfort and/or abnormal stress test results). The patients with coronary lesions with a diameter stenosis $\geq 50 \%$ in vessels $\geq 1.5 \mathrm{~mm}$ were included in the study. All patients were clinically stable. Exclusion criteria were the presence of neoplastic disease, heart failure, recent major surgical procedure, liver or kidney disease. Patients with previous myocardial infarction and angina episodes $48 \mathrm{~h}$ before hospitalization, who had undergone coronary angioplasty or bypass surgery and those with valvular, myocardial, or pericardial disease were also excluded. The study was conducted according to the recommendations set forth by the Declaration of Helsinki on Biomedical Research Involving Human Subjects. The Institutional Ethics Committee approved the study protocol, and each participant provided written, informed consent.

A detailed medical history was taken and a complete physical examination was conducted. In addition, systolic blood pressure (SBP) and diastolic blood pressure (DBP) were recorded. Fasting venous blood samples were obtained from all patients to determine laboratory parameters.

\section{Echocardiography and $A O$}

Standard two-dimensional examinations were performed using commercially available equipment (Vivid-7, GE Vingmed Sound, Horten, Norway) with a $2.5-3.5 \mathrm{MHz}$ transducer before angiography. Simultaneous echocardiographic recordings were also obtained. Ejection fraction (EF) was determined using Simpson's method, according to the suggestions of the American Society of Echocardiography [15].

Ascending aorta (Ao) diameters were measured from the same view on the $\mathrm{M}$ mode tracing at a level of $3 \mathrm{~cm}$ above the aortic valve. The systolic diameter (AoS) was measured at the maximum anterior motion of the aorta and the diastolic diameter (AoD) was measured at the peak of the QRS complex on the simultaneously recorded echocardiograms. Pulse pressure (PP) was calculated as
SBP minus DBP. The AD was calculated: $\mathrm{AD}=2 \times(\mathrm{AoS}-\mathrm{AoD}) /$ $(\mathrm{AoD} \times \mathrm{PP})\left(\mathrm{cm}^{2} \mathrm{dyn}^{-1} \times 10^{-6}\right)[16]$. The patients were divided into two groups according to the median $A D$ value $\left(\mathrm{AD}_{\text {low }}\right.$ and $A D_{\text {high }}$ groups).

All echocardiograms were performed and analyzed by one observer (M.G.). All echocardiographic measurements were repeated 1 week later by the same observer (M.G.) blinded to the results of the previous measurements and intraobserver coefficient of variation was between 3.0 and $6.7 \%$.

\section{SS and Angiographic Analysis}

Coronary lesions leading to $\geq 50 \%$ diameter stenosis in vessels $\geq 1.5 \mathrm{~mm}$ were scored separately and added together to provide the cumulative SS, which was calculated using the SS algorithm on the baseline diagnostic angiogram [13]. Two experienced interventional cardiologists (Z.E., M.Ç.) analyzed the SS; the opinion of a third analyst (M.G.) was obtained and the final judgment was made by consensus in cases of disagreement. The final score was calculated from the individual lesion scores by analysts who were blinded to procedural data and clinical outcome. Inter- and intraobserver coefficient of variation for the assessment of the SS was 5.7 and $4.3 \%$, respectively.

\section{Statistical Analysis}

All analyses were conducted using SPSS 17.0 (SPSS for Windows 17.0, Chicago, Ill., USA). Continuous variables were expressed as mean \pm SD and categorical variables were expressed as percentages. Distribution of continuous variables was assessed with 1-sample Kolmogorov-Smirnov test. Comparison of categorical variables among the groups was performed using the $\chi^{2}$ test. Comparisons of continuous variables between the two groups were performed using the independent samples t test. The Spearman's correlation analysis was used for the categorical data and the Pearson correlation analysis for the continuous data. Multiple linear regression analysis was used to determine the independent predictors of $\mathrm{AD}$. All significant parameters in the univariate analysis were selected in the multivariate model.

\section{Results}

The mean AD and SS values were $2.4 \pm 1.5 \mathrm{~cm}^{2} \mathrm{dyn}^{-1}$ $\times 10^{-6}$ and $13.4 \pm 9.7$, respectively. In all patients, New York Heart Association class was I-II. One hundred and fifty-five (41.2\%) patients had one-vessel disease, 129 (34.3\%) had two-vessel disease and 92 (24.5\%) had threevessel disease. Of the 376 obstructive CAD patients, 28 (7.4\%) declined bypass surgery, 8 (2.1\%) declined percutaneous coronary intervention (PCI) and 18 (4.8\%) had unsuitable coronary anatomy for revascularization. Forty-three (11.4\%) patients underwent coronary artery bypass grafting. In 7 (1.9\%) patients, the operator was unable to cross lesions during the PCI procedure. PCI was performed in 272 (72.3\%) patients who received at least one stent. Drug-eluting stents were used in 91 (24.2\%) patients. There was no serious complication. 
Table 1. Comparison of baseline and clinical characteristics, risk factors, laboratory findings and SS

\begin{tabular}{|c|c|c|c|}
\hline & $\begin{array}{l}\mathrm{AD}_{\text {high }} \text { group } \\
(\mathrm{n}=188)\end{array}$ & $\begin{array}{l}\mathrm{AD}_{\text {low }} \text { group } \\
(\mathrm{n}=188)\end{array}$ & $\begin{array}{l}\mathrm{p} \\
\text { value }\end{array}$ \\
\hline Age, years & $58.7 \pm 10.0$ & $64.6 \pm 8.8$ & $<0.001$ \\
\hline Male gender, n (\%) & $125(66.5)$ & $105(55.9)$ & 0.022 \\
\hline $\mathrm{SBP}, \mathrm{mm} \mathrm{Hg}$ & $121.2 \pm 15.5$ & $131.4 \pm 16.4$ & $<0.001$ \\
\hline $\mathrm{DBP}, \mathrm{mm} \mathrm{Hg}$ & $75.7 \pm 9.2$ & $78.6 \pm 10.6$ & 0.005 \\
\hline Pulse pressure, mm Hg & $45.4 \pm 10.4$ & $52.8 \pm 10.9$ & $<0.001$ \\
\hline Smoking, n (\%) & $69(36.7)$ & $60(31.9)$ & 0.192 \\
\hline Hypertension, n (\%) & $82(43.6)$ & $103(54.8)$ & 0.019 \\
\hline Diabetes, n (\%) & $48(25.5)$ & $76(40.4)$ & 0.001 \\
\hline Family history, n (\%) & $78(41.5)$ & $89(47.3)$ & 0.214 \\
\hline Hyperlipidemia, n (\%) & $119(63.3)$ & $101(53.7)$ & 0.114 \\
\hline Total cholesterol, mg/dl & $204.5 \pm 43.1$ & $192.7 \pm 44.3$ & 0.022 \\
\hline Triglyceride, mg/dl & $184.8 \pm 116.6$ & $153.7 \pm 80.8$ & 0.003 \\
\hline LDL-C, mg/dl & $126.8 \pm 53.9$ & $119.8 \pm 39.1$ & 0.152 \\
\hline HDL-C, mg/dl & $40.6 \pm 15.1$ & $42.3 \pm 14.0$ & 0.260 \\
\hline Fasting glucose, mg/dl & $126.1 \pm 68.1$ & $137.3 \pm 69.1$ & 0.115 \\
\hline Creatinine, $\mathrm{mg} / \mathrm{dl}$ & $0.84 \pm 0.22$ & $0.95 \pm 0.26$ & $<0.001$ \\
\hline Ejection fraction, \% & $64.5 \pm 4.7$ & $63.4 \pm 4.4$ & 0.020 \\
\hline AoSD, mm & $33.7 \pm 2.8$ & $35.2 \pm 2.4$ & $<0.001$ \\
\hline AoDD, mm & $31.3 \pm 2.9$ & $34.0 \pm 2.4$ & $<0.001$ \\
\hline SS & $8.3 \pm 5.9$ & $18.5 \pm 10.2$ & $<0.001$ \\
\hline
\end{tabular}

Continuous variables expressed as mean \pm SD. LDL-C $=$ Lowdensity lipoprotein cholesterol; HDL-C = high-density lipoprotein cholesterol; AoSD = aortic systolic diameter; $\mathrm{AoDD}=$ aortic diastolic diameter.
Baseline characteristics of subjects are shown in table 1. Age, gender, SBP, DBP, PP, diabetes and hypertension incidences, EF, AoS, AoD, total cholesterol, triglyceride and creatinine values were statistically different between the groups. SS was significantly higher in the $\mathrm{AD}_{\text {low }}$ group compared to the $\mathrm{AD}_{\text {high }}$ group.

\section{Bivariate and Multivariate Analysis of $A D$}

Bivariate analysis revealed that $\mathrm{AD}$ was significantly associated with age $(\mathrm{r}=-0.243, \mathrm{p}<0.001)$, hypertension $(\mathrm{r}=-0.314, \mathrm{p}<0.001)$, diabetes $(\mathrm{r}=-0.167, \mathrm{p}=0.001)$, PP $(\mathrm{r}=-0.397, \mathrm{p}<0.001), \mathrm{SS}(\mathrm{r}=-0.482, \mathrm{p}<0.001)$, EF $(\mathrm{r}=$ $0.156, \mathrm{p}=0.002)$, creatinine $(\mathrm{r}=-0.245, \mathrm{p}<0.001)$ and oral antidiabetic use $(\mathrm{r}=-0.145, \mathrm{p}=0.004)$. Multiple linear regression analysis revealed that $\mathrm{AD}$ was independently associated with age $(\beta=-0.104, \mathrm{p}=0.019)$, hypertension $(\beta=-0.202, \mathrm{p}<0.001)$ and SS $(\beta=-0.457, \mathrm{p}<$ 0.001 ). Relationships between AD and SS were demonstrated in hypertensive patients (fig. 1).

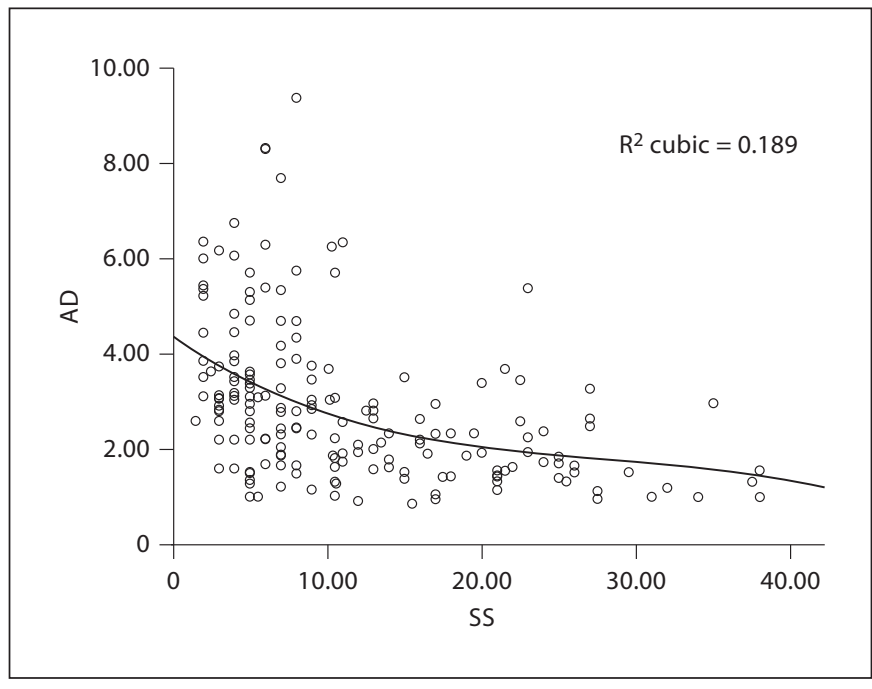

Fig. 1. Relationship between $\mathrm{AD}$ and SS in hypertensive patients.

\section{$A D$ in Hypertensive and Nonhypertensive Patients}

$A D$ value of hypertensive patients was lower than that of nonhypertensive patients $\left(1.95 \pm 1.13 \mathrm{~cm}^{2} \mathrm{dyn}^{-1} \times 10^{-6}\right.$ vs. $\left.2.86 \pm 1.59 \mathrm{~cm}^{2} \mathrm{dyn}^{-1} \times 10^{-6}, \mathrm{p}<0.001\right)$. AD was more strongly associated with SS in hypertensive patients compared to nonhypertensive patients $(\mathrm{r}=-0.524$ vs. $\mathrm{r}=$ $-0.414, \mathrm{p}<0.001$ for all).

\section{Discussion}

The present study showed that AD was independently associated with extent and complexity of CAD assessed with SS and hypertension in patients with stable CAD, as well as age. The relationship between SS and AD was stronger in patients with hypertensive stable CAD compared with nonhypertensive patients.

$\mathrm{AD}$ was impaired in atherosclerotic diseases such as CAD [7-11], carotid [17] and aortic atherosclerosis [9]. Experimental and clinical studies suggest that reduced $\mathrm{AD}$ is an early sign of atherosclerotic change [1-5]. Decreased AD has been related to increased cardiovascular mortality in different patient populations $[18,19]$. Decreased AD was also observed in hypertensive patients $[6$, $20]$. On the other hand, it is well known that aortic stiffness is an independent predictor of progression to hypertension in nonhypertensive individuals [21].

The relationship between severity of $\mathrm{CAD}$ and $\mathrm{AD}$ had been investigated in a limited number of studies [711]. Ahmadi et al. [7] reported that impaired AD mea- 
Table 2. Bivariate and multivariate relationships of $\mathrm{AD}$

\begin{tabular}{lrrll}
\hline Variables & $\begin{array}{l}\text { Correlation } \\
\text { coefficient }\end{array}$ & $\mathrm{p}$ value & $\begin{array}{l}\text { Standardized } \beta \\
\text { regression } \\
\text { coefficients }^{\mathrm{a}}\end{array}$ & $\mathrm{p}$ value \\
\hline Age & -0.243 & $<0.001$ & -0.104 & 0.019 \\
Gender & 0.089 & 0.086 & & \\
HT & -0.314 & $<0.001$ & -0.202 & $<0.001$ \\
PP & -0.397 & $<0.001$ & & \\
DM & -0.167 & 0.001 & 0.034 & 0.487 \\
BMI & -0.032 & 0.536 & & \\
SS & -0.482 & $<0.001$ & -0.457 & $<0.001$ \\
SS with HT & -0.524 & $<0.001$ & & \\
SS without HT & -0.414 & $<0.001$ & & \\
EF & 0.156 & 0.002 & -0.002 & 0.967 \\
TC & 0.070 & 0.183 & & 0.215 \\
TG & 0.130 & 0.013 & 0.059 & 0.444 \\
Creatinine & -0.245 & $<0.001$ & -0.039 & 0.532 \\
OAD use & -0.145 & 0.004 & 0.028 & \\
\hline
\end{tabular}

$\mathrm{HT}=$ Hypertension; $\mathrm{DM}=$ diabetes mellitus; $\mathrm{BMI}=$ body mass index TC $=$ total cholesterol; $\mathrm{TG}=$ triglyceride $\mathrm{OAD}=$ oral antidiabetic drug.

sured by computed tomography was strongly correlated with the severity of coronary atherosclerosis. Yildiz et al. [8] showed that AD was independently correlated with the severity of CAD assessed by the Gensini score in 56 stable CAD patients. Siegel et al. [9] reported that a stiffer, less distensible aorta was associated with coronary atherosclerosis, particularly in the presence of calcified and mixed plaques [9]. This finding is consistent with our results because SS shows the complexity and extent of CAD. A previous study reported that small arterial elasticity measured on radial artery can predict the extent of CAD assessed by the Gensini score [10]. Giannattasio et al. [11] reported a significant relationship between subdiaphragmatic AD and the number of diseased coronary arteries in patients admitted with angina. Celik et al. [22] showed that there were no significant differences regarding the aortic elastic properties between pa- tients with poor collateral vessels and those with good collateral vessels. In that study, the relationship between extent and complexity of CAD and AD was not investigated.

Functional and structural changes in the artery wall precede and accompany atherosclerosis [1]. Arterial stiffness is determined by the viscoelastic properties of the artery. These properties are a function of smooth muscles and elastin-to-collagen ratio, whereas the subendothelial matrix also affects arterial stiffness [1, 23]. Dysregulation of elastin-to-collagen ratio leads to overproduction of abnormal collagen and diminished quantities of normal elastin, which contributes to vascular stiffness [1]. An increase in elastic artery stiffness is related to functional and structural changes in arterial wall composition and occurs over a long period with advancing age [24], hypertension $[6,20]$ and atherosclerosis [7-11, 17]. In the present study, the relationships between $A D$ and SS, age and hypertension support the above-mentioned mechanism.

The limitations of this study were that PP was noninvasively measured by cuff sphygmomanometer, but the noninvasively calculated aortic function indices are well correlated with indices derived from aortography. Prehospital medications could have affected our results. However, prehospital medications except oral antidiabetic use were not different between the groups. AD was associated with oral antidiabetic use in bivariate analysis. A similar relation was not observed in multiple linear regression analysis.

\section{Conclusion}

The $\mathrm{AD}$ was independently related to the extent and complexity of CAD, as well as hypertension and age. The relationship between $\mathrm{AD}$ and the extent and complexity of CAD was stronger in hypertensive patients. Impaired $\mathrm{AD}$ might be an independent predictor for the extent and complexity of coronary atherosclerosis, in hypertensive patients in particular.
References

Aortic Distensibility and Coronary

Artery Disease
Med Princ Pract 2013;22:260-264 DOI: $10.1159 / 000345842$ 
4 Hironaka K, Yano M, Kohno M, Tanigawa T, Obayashi M, Konishi M, Umemoto S, Matsuzaki M: In vivo aortic wall characteristics at the early stage of atherosclerosis in rabbits. Am J Physiol 1997;273:H1142H1147.

-5 Acikgoz N, Ermis N, Yagmur J, Muezzinoglu K, Karakus Y, Cansel M, Pekdemir H, Ozdemir R: Uric acid level and its association with carotid intima-media thickness in patients with cardiac syndrome X. Med Princ Pract 2012;21:115-119.

6 Eren M, Gorgulu S, Uslu N, Celik S, Dagdeviren B, Tezel T: Relation between aortic stiffness and left ventricular diastolic function in patients with hypertension, diabetes, or both. Heart 2004;90:37-43.

7 Ahmadi N, Nabavi V, Hajsadeghi F, Flores F, Azmoon S, Ismaeel H, Shavelle D, Mao SS, Ebrahimi R, Budoff MJ: Impaired aortic distensibility measured by computed tomography is associated with the severity of coronary artery disease. Int J Cardiovasc Imaging 2011;27:459-469.

8 Yildiz A, Gur M, Yilmaz R, Demirbag R: The association of elasticity indexes of ascending aorta and the presence and the severity of coronary artery disease. Coron Artery Dis 2008;19:311-317.

-9 Siegel E, Thai WE, Techasith T: Aortic distensibility and its relationship to coronary and thoracic atherosclerosis plaque and morphology by MDCT: insights from the ROMICAT Trial. Int J Cardiol 2012, E-pub ahead of print.

10 Fazlioğlu M, Sentürk T, Kumbay E, Kaderli AA, Yilmaz Y, Ozdemir B, Baran I, Aydinlar A: Small arterial elasticity predicts the extent of coronary artery disease: relationship with serum uric acid. Atherosclerosis 2009;202: 200-204.

11 Giannattasio C, Capra A, Facchetti R, Viscardi L, Bianchi F, Failla M, Colombo V, Grieco A, Mancia G: Relationship between arterial distensibility and coronary atherosclerosis in angina patients. J Hypertens 2007;25:593-598.
12 Ohtsuka S, Kakihana M, Watanabe H, Sugishita Y: Chronically decreased aortic distensibility causes deterioration of coronary perfusion during increased left ventricular contraction. J Am Coll Cardiol 1994;24: 1406-1414

13 Sianos G, Morel MA, Kappetein AP, Morice MC, Colombo A, Dawkins K, van den Brand M, Van Dyck N, Russell ME, Mohr FW, Serruys PW: The SYNTAX Score: an angiographic tool grading the complexity of coronary artery disease. EuroIntervention 2005; 1:219-227.

14 Capodanno D, Di Salvo ME, Cincotta G, Miano M, Tamburino C, Tamburino C: Usefulness of the SYNTAX score for predicting clinical outcome after percutaneous coronary intervention of unprotected left main coronary artery disease. Circ Cardiovasc Interv 2009;2:302-308.

-15 Schiller NB, Shah PM, Crawford M, DeMaria A, Devereux R, Feigenbaum H, Gutgesell H, Reichek N, Sahn D, Schnittger I, et al: Recommendations for quantitation of the left ventricle by two-dimensional echocardiography. American Society of Echocardiography Committee on Standards, Subcommittee on Quantitation of Two-Dimen sional Echocardiograms. J Am Soc Echocardiogr 1989;2:358-367.

16 Stefanadis C, Dernellis J, Vlachopoulos C, Tsioufis C, Tsiamis E, Toutouzas K, Pitsavos C, Toutouzas P: Aortic function in arterial hypertension determined by pressure-diameter relation: effects of diltiazem. Circulation 1997;96:1853-1858.
7 Gullu H, Erdogan D, Caliskan M: Interrelationship between noninvasive predictors of atherosclerosis: transthoracic coronary flow reserve, flow-mediated dilation, carotid intima-media thickness, aortic stiffness, aortic distensibility, elastic modulus, and brachial artery diameter. Echocardiography 2006;23: 835-842.

18 Laurent S, Boutouyrie P, Asmar R, Gautier I, Laloux B, Guize L, Ducimetiere P, Benetos A: Aortic stiffness is an independent predictor of all-cause and cardiovascular mortality in hypertensive patients. Hypertension 2001; 37:1236-1241.

19 Stefanadis C, Dernellis J, Tsiamis E, Stratos C, Diamantopoulos L, Michaelides A, Toutouzas P: Aortic stiffness as a risk factor for recurrent acute coronary events in patients with ischemic heart disease. Eur Heart J 2000;21:390-396.

-20 Gur M, Yilmaz R, Demirbag R, Yildiz A, Menduh Bas M, Polat M: Relationship between impaired elastic properties of aorta with left ventricle geometric patterns and left ventricle diastolic functions in patients with newly diagnosed essential hypertension. Int J Clin Pract 2006;60:1357-1363.

21 Dernellis J, Panaretou M: Aortic stiffness is an independent predictor of progression to hypertension in nonhypertensive subjects. Hypertension 2005;45:426-431.

22 Celik S, Kaplan S, Yilmaz R, Erdogan T, Kiris A: Relationship between aortic stiffness and the development of coronary collateral in patients with coronary artery disease. Angiology 2008;58:671-676.

23 O'Rourke MF: The arterial pulse in health and disease. Am Heart J 1971;82:687-702.

- 24 Mohiaddin RH, Underwood SR, Bogren HG, Firmin DN, Klipstein RH, Rees RS, Longmore DB: Regional aortic compliance studied by magnetic resonance imaging: the effects of age, training and coronary artery disease. Br Heart J 1989;62:90-96. 